\title{
Pediatric Drug Development and Dosage Form Design
}

\author{
Maren Preis $^{1,3}$ and Jörg Breitkreutz
}

Received 23 December 2016; accepted 25 December 2016; published online 23 January 2017

KEYWORDS: children; dosage forms; pediatric drug development; pediatrics.

For many years, children have been described as "therapeutic orphans" to indicate that medicinal research, regulation, and formulation development has mainly focused on diseases in adults (1). The development of age-appropriate medicine for the heterogeneous pediatric population is a particular challenge. It starts with the right choice of drugs and their dose, but equally important is the route of administration. This theme issue of AAPS PharmSciTech provides an overview on (a) regulatory considerations for pediatric products, (b) appropriate dosage forms and drug formulations for children, and (c) test methods to assess critical attributes of such preparations.

Despite the increasing awareness for age-appropriate formulations, available licensed pediatric drugs are still lagging behind those for adult patients. Van Riet-Nales et al. gives an overview on the European perspective regarding the development and design of pediatric drugs (2), and the key aspects of the recent European "Guideline on the Pharmaceutical Development of Medicines for Paediatric Use" are discussed. Subsequent articles in this theme issue address the pharmaceutical formulation challenges associated with a Pediatric Investigation Plan (Europe) or Pediatric Study Plan (United States). Various initiatives have been set up to promote and facilitate the preparation of better and safe medicines for children $(3,4)$.

Recent studies revealed that even the youngest children are capable to take small-sized solid dosage forms. The results of the conducted clinical studies on the acceptability of mini-tablets in children are summarized and discussed in an overview article

\footnotetext{
$\overline{{ }^{1} \text { Pharmaceutical Sciences Laboratory, Faculty of Science and Engi- }}$ neering, Åbo Akademi University, BioCity, Artillerigatan 6A, 20520, Turku, Finland.

${ }^{2}$ Institute of Pharmaceutics and Biopharmaceutics, Heinrich-HeineUniversität Düsseldorf, Universitätsstraße 1, Geb. 26.22, 40225, Düsseldorf, Germany.

${ }^{3}$ To whom correspondence should be addressed. (e-mail: maren.preis@abo.fi)
}

(5). Besides the mentioned small-sized tablets, orally disintegrating films appear as a promising dosage form to facilitate the drug administration in children, offering more flexible dosing and ease of administration (6). With a dosage form that additionally enables the drug to be released immediately in the oral cavity or to be absorbed via the buccal mucosa, higher requirements for palatability and understanding the necessity of appropriate excipients have to be considered (7). The continuous research in oromucosal drug delivery will potentially lead to more products and applications, such as vaccine delivery (8). New technologies to manufacture tailored and flexible dosage forms that comply with the specific needs of pediatric patients are entering the market, such as printing technologies. However, it is crucial to define, which quality attributes and control tools are required to ensure the performance and safety of these products $(9,10)$.

Taking into account that drug administration in children can be challenging for caregivers and often food is used to facilitate the process, it is worthwhile to investigate different dosing scenarios (11), but also suitable gastrointestinal digestion models (12). Mixing drugs into foodstuff is one approach to additionally mask the taste of pharmaceuticals and facilitate the swallowing procedure. However, multiple aspects such as the viscosity and $\mathrm{pH}$ value but also fat and sugar contents have to be considered and evaluated. To avoid cost-intensive human sensory panels, studies in this theme issue address animal models and electronic sensors to assess the taste of pediatric formulations $(13,14)$.

Pediatric drug development and the identification and characterization of appropriate dosage forms go hand in hand. Recent research progress shows the importance and the need for clinically relevant pediatric products and in addition advisably in-vitro methods to keep up with new technologies and demands. Pediatric formulation initiatives and the competent authorities are working on providing improved and detailed guidance for pediatric product development. The demand for more flexible and individual drug dosing will evolve in significant improvement of medicines for pediatric use in the near future. 


\section{REFERENCES}

1. Ernest TB, et al. Preparation of medicines for children-a hierarchy of classification. International Journal of Pharmaceutics. 2012;435(2):124-30.

2. Van Riet-Nales DA, et al. Paediatric drug development and formulation design-a European perspective. AAPS PharmSciTech. 2016. doi:10.1208/s12249-016-0558-3.

3. Walsh J. Reflection on the pharmaceutical formulation challenges associated with a paediatric investigation plan for an offpatent drug. AAPS PharmSciTech. 2016. doi:10.1208/s12249016-0527-x.

4. Salunke S, et al. European paediatric formulation initiative (EuPFI)-formulating ideas for better medicines for children. AAPS PharmSciTech. 2016. doi:10.1208/s12249-016-0584-1.

5. Klingmann V. Acceptability of mini-tablets in young children: results from three prospective cross-over studies. AAPS PharmSciTech. 2016. doi:10.1208/s12249-016-0639-3.

6. Visser JC, et al. Personalized medicine in pediatrics: the clinical potential of orodispersible films. AAPS PharmSciTech. 2016. doi:10.1208/s12249-016-0515-1.

7. Montero-Padilla S, Velaga S, Morales JO. Buccal dosage forms: general considerations for pediatric patients. AAPS PharmSciTech. 2016. doi:10.1208/s12249-016-0567-2.
8. Gala RP, et al. Physicochemical and preclinical evaluation of a novel buccal measles vaccine. AAPS PharmSciTech. 2016. doi:10.1208/s12249-016-0566-3.

9. Wickström H, et al. Colorimetry as quality control tool for individual inkjet-printed pediatric formulations. AAPS PharmSciTech. 2016. doi:10.1208/s12249-016-0620-1.

10. Preis M, Öblom H. 3D-printed drugs for children-are we ready yet? AAPS PharmSciTech. 2017. doi:10.1208/s12249-0160704-y.

11. Karkossa F, et al. Simulating different dosing scenarios for a child-appropriate valproate ER formulation in a new pediatric two-stage dissolution model. AAPS PharmSciTech. 2016. doi:10.1208/s12249-016-0671-3.

12. Kamstrup D, et al. In vitro model simulating gastro-intestinal digestion in the pediatric population (neonates and young infants). AAPS PharmSciTech. 2016. doi:10.1208/s12249-0160649-1.

13. Immohr LI, et al. Suitability of E-tongue sensors to sssess tastemasking of pediatric liquids by different beverages considering their physico-chemical properties. AAPS PharmSciTech. 2016. doi:10.1208/s12249-016-0526-y.

14. Tiwari RV, et al. Rat palatability study for taste assessment of caffeine citrate formulation prepared via hot-melt extrusion technology. AAPS PharmSciTech. 2015. doi:10.1208/s12249-0150447-1. 